\title{
A Clinico-Etiological Study of Erythroderma in Adults in a Tertiary Care Centre
}

\author{
Jagaragallu Amrutha ${ }^{1}$, Narasimha Rao Netha Gurram², Padmaja Pinjala ${ }^{3}$, \\ Bhumesh Kumar Katakam ${ }^{4}$, Rajeev Singh Thakur ${ }^{5}$ \\ 1, 2, 3, 4, 5 Department of Dermatology, Venereology, Leprosy, \\ Gandhi Medical College, Secunderabad, Telangana, India.
}

\section{ABSTRACT}

\section{BACKGROUND}

Erythroderma is a clinical entity that may cause severe systemic manifestations. The difficulty with erythroderma lies in finding the underlying aetiology. It is imperative to demonstrate precise aetiology whenever possible so that distinct therapy may be initiated. At times, despite finding the aetiology, relapses constitute a great menace. The purpose of our study was to assess the clinical profile and aetiology of erythroderma. Besides, the study also illustrated factors leading to relapses; such studies are rare in literature.

\section{METHODS}

This hospital-based, cross-sectional study included 88 patients of erythroderma of either sex and age more than 18 years; their clinical, laboratory, histopathological findings, treatment and outcome were studied.

\section{RESULTS}

The mean age of onset was $47.3 \pm 12.35$ years with the male to female ratio being 2.38:1. The most common cause of erythroderma was pre-existing dermatoses (67 $\%)$ followed by drugs (10.2\%), infections (3.4\%), malignancies (4.54\%), and idiopathic (14.7\%). Psoriasis was the predominant aetiology (45.4\%) among the pre-existing dermatoses with a maximum number of relapses $(\mathrm{P}=0.02)$. Psoriasis was significantly associated with pruritus $(\mathrm{P}=0.001)$, subungual hyperkeratosis $(\mathrm{P}=$ 0.0001), palmoplantar keratoderma $(P=0.001)$. Clinicohistological association was found in $64.6 \%$ of cases. Mortality was seen in $6.8 \%$ of cases.

\section{CONCLUSIONS}

As in previous studies, pre-existing dermatoses were the most common causes in our study; albeit, a special emphasis on factors leading to relapses was given to prevent further episodes. The most common factor of relapse was uncontrolled comorbid disorders (diabetes and hypertension) followed by medication nonadherence. Hence, our study suggests a need for more effective comorbidity management and creating awareness regarding judicial use of drugs which can go far in preventing mortality and morbidity.

\section{KEY WORDS}

Erythroderma, Adults, Aetiology, Relapses, Comorbidities.
Corresponding Author: Dr. Amrutha Jagaragallu, Gandhi Medical College, Secunderabad, Telangana, India. E-mail: j.amrutha05@gmail.com

DOI: $10.14260 /$ jemds/2021/653

How to Cite This Article: Amrutha J, NethaGurram NR, Pinjala P, et al. A clinico-etiological study of erythroderma in adults in a tertiary care centre. I Evolution Med Dent Sci 2021;10(37):3213-3219, DOI: $10.14260 /$ jemds/2021/653

Submission 15-06-2021, Peer Review 09-08-2021, Acceptance 16-08-2021, Published 13-09-2021.

Copyright (C) 2021 Jagaragallu Amrutha et al. This is an open access article distributed under Creative Commons Attribution License [Attribution 4.0 International (CC $B Y 4.0)]$ 


\section{BACKGROUND}

Erythroderma is a generalized inflammatory disorder of the skin manifesting with erythema and scaling affecting more than $90 \%$ of the skin surface. ${ }^{1}$ It is one of the few dermatological conditions requiring hospitalization and multisystem management. Erythroderma is considered a complex system that may be the result of many different causes. The diagnosis of the underlying cause may be very difficult but it is important to find aetiology for the appropriate intervention of each case.

\section{Objectives}

To evaluate demographic profile, clinical features, aetiology of erythroderma and correspond the clinical diagnosis with histopathology.

\section{METHODS}

This cross-sectional study was conducted between January 2017 and June 2019 (30 months) at a tertiary care teaching hospital located in Southern India. 88 successive erythroderma patients aged above 18 years were included in the study. Pregnant and lactating women were excluded from the study. The study was recognized by the institute scientific and ethics committees and written informed consent was procured from all patients.

Study patients were enlisted from dermatology outpatient clinics and referrals from other departments and convenience sampling was followed. All patients were admitted and were evaluated with detailed history and complete physical examination. History included the onset and evolution of erythroderma, history of pre-existing dermatoses, previous episodes of erythroderma, aggravating factors, comorbidities and drug intake. A detailed clinical examination was done to know the various clinical manifestations and also find out the possible causes for the erythroderma.

History of silvery scaly plaques and heavier involvement in body parts where psoriasis was common helped in making out psoriatic erythroderma. Typical nail changes of psoriasis and psoriatic arthritis if present are clues to psoriasis. Strong history of contact allergy, presence of previous eczematous lesions and also severe oozy lesions will help to diagnose the allergic contact dermatitis as the cause of erythroderma, which was confirmed by patch testing. Ingestion of suspected drugs before the onset and acute onset with fever will help in the diagnosis.

Diagnosis of idiopathic erythroderma could be made when the condition is extending over 1 month in an elderly with severe pruritus with palmoplantar keratoderma. Cutaneous lymphoma presents with similar findings of idiopathic erythroderma, keen histopathological examination and follow-up biopsy will help to make out the diagnosis.

Laboratory investigations such as complete hemogram, blood glucose, renal function tests, liver function tests, serum electrolytes, erythrocyte sedimentation rate, serum protein levels, urine microscopy, serum markers for viral hepatitis B and $\mathrm{C}$ and HIV antibody testing were performed. Wherever necessary, chest radiograph, ultrasound, peripheral blood smear, fine needle aspiration cytology of lymph nodes, patch testing, microscopy for scabies mite and fungus were done. Skin biopsy for histopathological examination was performed in 62 cases $(70.45 \%)$. We have also examined data concerning management, outcome, relapses and complications when available.

\section{Statistical Analysis}

The findings were recorded on a specially designed master chart and statistical tests were done using Epi info software version 7.2.2.6 and analyses were done at a $5 \%$ level of significance and a P-value of $<0.05$ was considered significant. Chi-square test was applied to obtain the P-value.

\section{RESULTS}

The mean age of onset was $47.3 \pm 12.35$ years with the age of the patients ranging from 21 to 78 years. The majority of the patients belonged to the age group of 40 - 49 years (38 cases) $(43.1 \%)$ and a minimum number of patients in $70-79$ years group ( 4 cases) ( $4.54 \%$ ). There were 62 males $(70.5 \%)$ and 26 females (29.5\%) with a male to female ratio being 2.38:1, showing male preponderance.

The mean duration of onset of erythroderma was 46 days (median $=60$ days) (range: 1 day-18 months). Progression of the disease was in less than 6 - 8 weeks in 72 patients $(81.8$ $\%$ ) albeit, 12 patients showing sudden progression within 3 4 days were seen in psoriasis. A longer duration of more than one year was seen in cutaneous lymphoma and psoriasis. In the study, psoriasis was the entity with a varied duration of onset ranging from few days to more than one year.

In the study, comorbidities were recorded in 58 patients (65.9\%). The most common comorbidities documented were hypertension (42 patients), diabetes (33 patients), tuberculosis (three patients), HIV / AIDS (four patients) and epilepsy (four patients). $75 \%$ of patients with psoriasis (30 patients out of 40) had at least one comorbidity in their past medical history.

Pre-existing dermatoses were recorded in 27 patients (30.6\%) which comprised psoriasis (22 patients), eczema (five patients).

Table 1 illustrates the characteristics of the patients and a summary of the results of the study.

\section{Clinical Features and Laboratory Investigations}

Besides generalized erythema and scaling, clinical features included pruritus (49 / 88 patients; $55.6 \%$ ), shivering (26/ 88 patients; $29.5 \%$ ), malaise (41 / 88 patients; $46.5 \%$ ), pedal oedema (43 / 88 patients; $48.8 \%$ ), fever (18 / 88 cases; 20.4 \%), palmoplantar keratoderma (55 / 88 patients; $62.5 \%$ ), nail changes (64 / 88 patients; $72.7 \%$ ), lymphadenopathy (28 / 88 patients; $31.8 \%$ ). (Figure 1a,1b). Hypoalbuminemia (16 / 88 patients; $18.1 \%$ ) is attributed to loss of proteins in the form of scales and hepatic insufficiency. 


\section{Aetiology}

In the study, patients were categorized into five etiologic groups as illustrated in Figure 2: (1) Pre-existent dermatoses (66.9\%) (2) infections (3.4\%) (3) drug reactions (10.2\%) (4) malignancy (4.5\%) (5) idiopathic or undetermined (14.7\%). Pre-existing dermatoses comprising psoriasis and eczemas contributed the highest percentage of erythroderma as seen in 59 patients $(66.9 \%)$. Psoriasis was the most common preexisting dermatosis causing erythroderma (40 / 88 patients;
$45.4 \%$ ) (Figure 1c). Erythroderma had arisen on pre-existing longstanding

psoriasis in 22 patients with a mean period of 557 days and median period of 90 days (ranges: 4 days and $71 \frac{1}{2}$ years). Acute onset of erythroderma was seen in 12 patients and all of them had a history of psoriatic arthritis $(\mathrm{P}=0.02) .14$ psoriasis patients had relapses and among them, 10 patients had significantly longer duration of psoriasis $(\mathrm{P}=0.002)$ [mean $=$ 2.5 years and median $=11 / 2$ year (range: $1-7$ years) $]$.

\begin{tabular}{|c|c|c|c|c|c|c|}
\hline Aetiology & $\begin{array}{c}\text { Psoriasis } \\
40 \text { cases }(45.4 \%)\end{array}$ & $\begin{array}{c}\text { Eczema } \\
19 \operatorname{cases}(21.5 \%)\end{array}$ & $\begin{array}{c}\text { Infections } \\
3 \text { cases }(3.4 \%)\end{array}$ & $\begin{array}{c}\text { Drug } \\
9 \text { cases }(10.2 \%)\end{array}$ & $\begin{array}{c}\text { Malignancy } \\
4 \text { cases }(4.54 \%)\end{array}$ & $\begin{array}{c}\text { Idiopathic } \\
13 \text { cases }(14.7 \%)\end{array}$ \\
\hline Age Mean(years) & 41.35 & 53.75 & 46.3 & 46.5 & 49.75 & 57.6 \\
\hline Sex ratio & 2 & 2.8 & 3 cases are males & 2 & 4 cases are males & 1.6 \\
\hline \multicolumn{7}{|l|}{ Clinical features } \\
\hline Pruritus ( 49 cases) & 30 & 6 & 3 & 3 & 2 & 5 \\
\hline Shivering ( 26 cases) & 10 & 3 & - & 5 & 2 & 6 \\
\hline Malaise ( 41 cases) & 16 & 6 & 1 & 7 & 3 & 8 \\
\hline Pedal oedema (43cases) & 22 & 10 & - & 3 & 2 & 6 \\
\hline Fever (18 cases) & 7 & - & - & 8 & - & 3 \\
\hline Oliguria (10 cases) & 3 & 1 & - & 3 & 1 & 2 \\
\hline Nail changes (64 cases) & 36 & 11 & 3 & 2 & 2 & 10 \\
\hline $\begin{array}{c}\text { Palmoplantar keratoderma } \\
\text { (55 cases) }\end{array}$ & 36 & 9 & 1 & 4 & - & 5 \\
\hline $\begin{array}{c}\text { Conjunctival congestion } \\
\text { (23 cases) }\end{array}$ & 10 & 2 & - & 6 & 2 & 3 \\
\hline $\begin{array}{c}\text { Scalp involvement (31 } \\
\text { cases) }\end{array}$ & 25 & 1 & - & - & 1 & 4 \\
\hline Oral mucosa (14 cases) & 5 & - & - & 6 & 1 & 2 \\
\hline $\begin{array}{l}\text { Lymphadenopathy (28 } \\
\text { cases) }\end{array}$ & 13 & 2 & 1 & 2 & 4 & 6 \\
\hline $\begin{array}{c}\text { Hepatosplenomegaly } \\
\text { (4 cases) }\end{array}$ & - & - & - & 1 & 1 & 2 \\
\hline Deck chair sign ( 4 cases) & 2 & 1 & - & - & 1 & - \\
\hline Nose sign ( 6 cases) & 3 & 2 & - & - & - & 1 \\
\hline \multicolumn{7}{|l|}{ Laboratory investigations } \\
\hline Anaemia (16 cases) & 6 & 1 & - & 3 & 2 & 4 \\
\hline $\begin{array}{l}\text { Hypoalbuminemia ( } 24 \\
\text { cases) }\end{array}$ & 13 & 3 & - & 3 & 1 & 4 \\
\hline Eosinophilia ( 7 cases) & & & & 4 & 3 & - \\
\hline $\begin{array}{c}\text { Atypical lymphocytes (2 } \\
\text { cases) }\end{array}$ & & & & & 2 & \\
\hline $\begin{array}{l}\text { Altered Liver function tests } \\
\text { (16 cases) }\end{array}$ & 5 & 2 & - & 4 & 1 & 4 \\
\hline $\begin{array}{l}\text { Altered kidney function } \\
\text { tests (14 cases) }\end{array}$ & 4 & 2 & - & 3 & - & 5 \\
\hline Outcome & $\begin{array}{l}\text { Lost to follow up - } 6 \\
\text { Clearance - } 32 \\
\text { No response - } 2\end{array}$ & $\begin{array}{l}\text { Lost to follow up - } 2 \\
\text { Clearance - } 15 \\
\text { No response - } 2\end{array}$ & Clearance - 3 & $\begin{array}{l}\text { Lost to follow up - } 0 \\
\text { Clearance - } 8 \\
\text { Mortality - } 1\end{array}$ & $\begin{array}{c}\text { Clearance - } 1 \\
\text { No response - } 2 \\
\text { Mortality - } 2\end{array}$ & $\begin{array}{l}\text { Lost to follow up - } 5 \\
\text { Clearance - } 3 \\
\text { No response - } 2 \\
\text { Mortality - } 3\end{array}$ \\
\hline \multicolumn{7}{|c|}{ Table 1. Demographical, Clinical, Laboratory, Therapeutic and Evolutive Features of the 88 Patients with Erythroderma According to Aetiology } \\
\hline
\end{tabular}

\begin{tabular}{|c|c|c|}
\hline Clinical Diagnosis & Number of Biopsies & Histopathological Diagnosis \\
\hline Psoriasis (40 cases) & 26 & $\begin{array}{l}\text { Psoriasis - } 24 \\
\text { Non-specific - } 2\end{array}$ \\
\hline Eczema (19 cases) & 12 & $\begin{array}{c}\text { Eczema - } 8 \\
\text { Non-specific - } 4\end{array}$ \\
\hline Infections ( 3 cases) & 3 & $\begin{array}{l}\text { Dermatophytosis - } 2 \\
\text { Scabies - } 1\end{array}$ \\
\hline Drug ( 9 cases) & 5 & $\begin{array}{l}\text { Drug reaction - } 3 \\
\text { Non-specific - } 2\end{array}$ \\
\hline Malignancy (4 cases) & 4 & Malignancy - 4 \\
\hline Idiopathic (13 cases) & 15 & $\begin{array}{c}\text { Eczema - } 3 \\
\text { Non-specific - } 12\end{array}$ \\
\hline
\end{tabular}

\begin{tabular}{|c|c|c|c|c|c|}
\hline Author(s), years & $\begin{array}{c}\text { Number of Patients } \\
\text { (N) }\end{array}$ & $\begin{array}{c}\text { Pre - Existing } \\
\text { Dermatoses (\%) }\end{array}$ & Drug (\%) & Malignancy (\%) & Idiopathic (\%) \\
\hline \multicolumn{6}{|l|}{ Other countries } \\
\hline Nicolis and Helwig et al.(1973) & 135 & 27 & 40 & 8 & 12 \\
\hline Hasan and Jansen (1983) & 50 & 54 & 10 & 4 & 32 \\
\hline King et al. (1986) & 82 & 31 & 34 & 18 & 16 \\
\hline Wilson et al. (1993) & 50 & 48 & 8 & 4 & 32 \\
\hline Pal and Haroon (1998) & 90 & 74 & 5.5 & $5.5 \%$ & 14.6 \\
\hline Sehgal et al. (2004) & 80 & 58 & 20 & 0 & 22 \\
\hline Akhyani et al. (2005) & 97 & $59.8 \%$ & 21.6 & 11.3 & 7.2 \\
\hline Khaled et al. (2010) & 82 & 43.9 & 21.95 & 4.87 & 25.6 \\
\hline \multicolumn{6}{|l|}{ In India } \\
\hline Hulmani et al. (2014) & 30 & 63 & 16.6 & 3.3 & 16.6 \\
\hline Banerjee S et al. (2015) & 32 & 62.5 & 12.5 & 0 & 25 \\
\hline Present study & 88 & 67 & 10.2 & 4.54 & 14.7 \\
\hline & e 3. Causes of Eryth & ma in Previous & Compare & he Present Study & \\
\hline
\end{tabular}



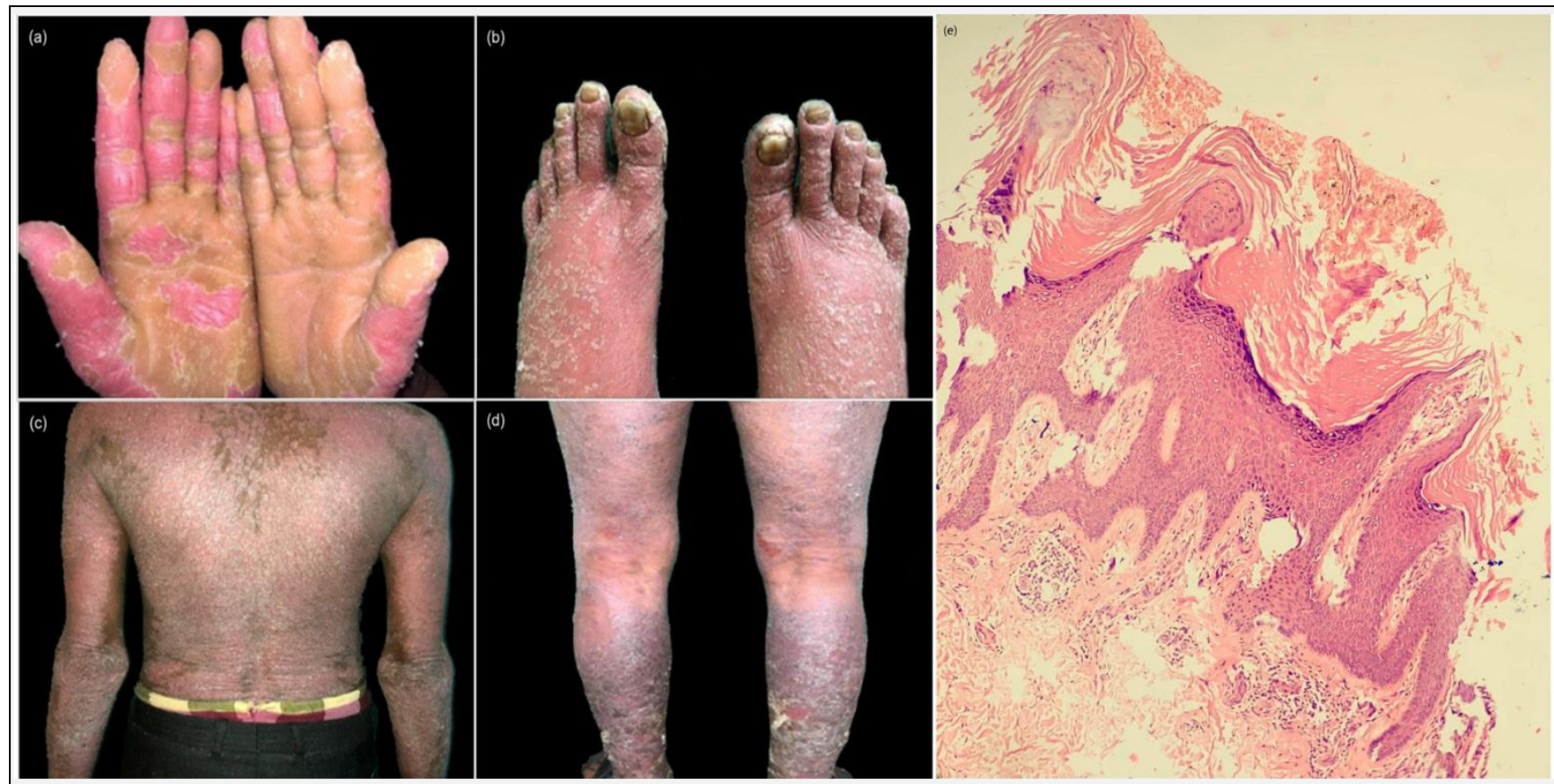

Figure 1. Clinical Features of Cases 1a) Palmar Keratoderma 1b) Subungual Hyperkeratosis 1c) Psoriatic Erythroderma 1d) Erythroderma Due to Stasis Eczema 1e) Histopathological Features of Biopsy (10 x)(H \& E) Psoriasiform Dermatitis Showing Hyperkeratosis, Parakeratosis, Elongation of Rete Ridges

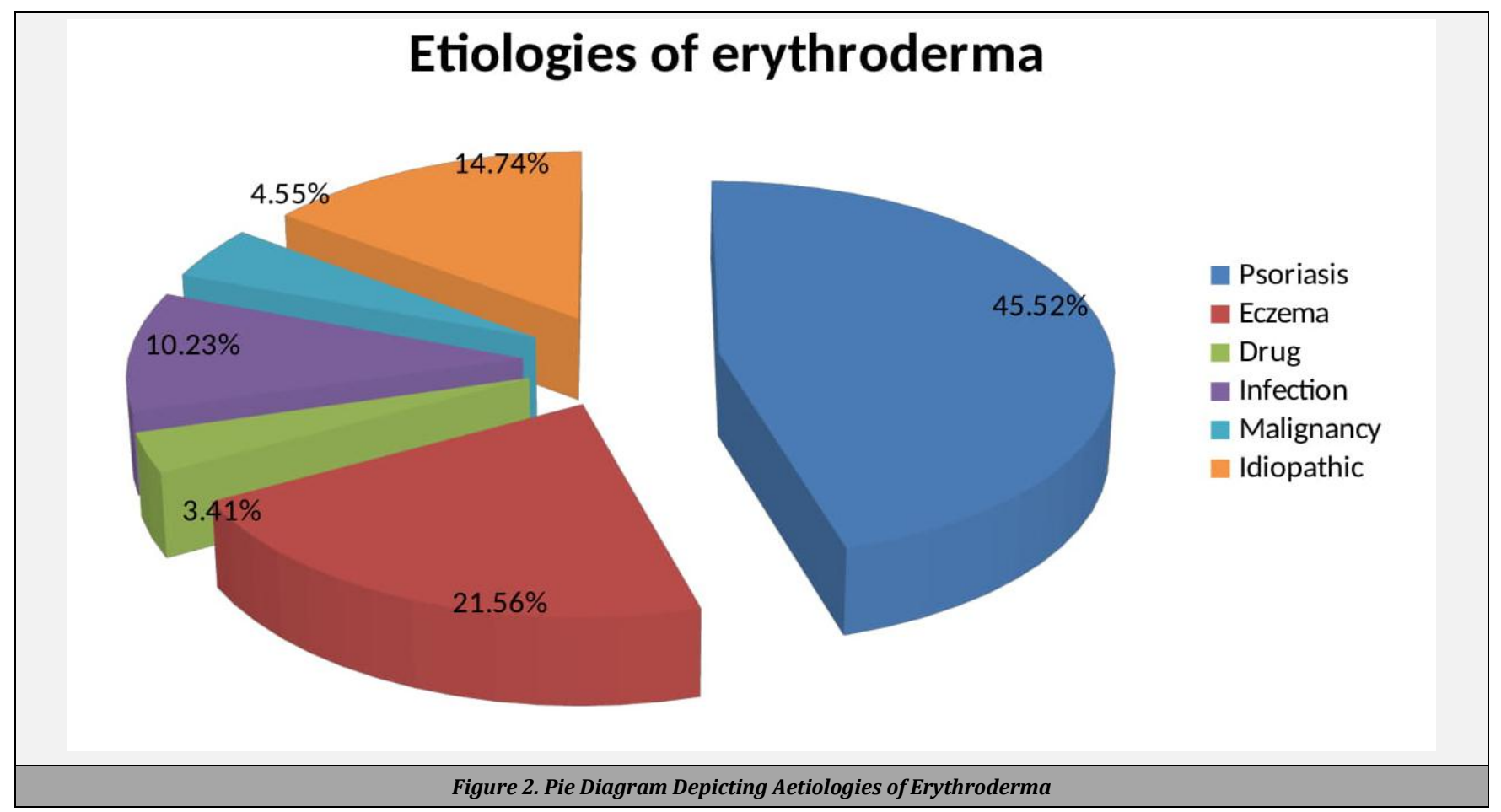

Eczema was the cause of erythroderma in $21.5 \%$ of patients (19 / 88 patients) (Figure 1d). Eczemas documented were: allergic contact dermatitis (ACD) (seven patients), airborne contact dermatitis (ABCD) (seven patients) and stasis eczema (five patients). ACD was due to paraphenylenediamine (two patients), Semecarpus anacardium / bhilawa seeds (one patient), cement (two patients), nickel (two patients). ACD was diagnosed by patch testing. ABCD due to parthenium weed was the cause of erythroderma in seven patients.

Infections implicated in causing erythroderma were extensive dermatophytosis (two patients), crusted scabies (one patient). Factors responsible for the flare-up of dermatophytosis to erythroderma were erratic use of topical corticosteroids.

Drug-induced erythroderma was identified in nine patients (10.2\%). Incriminated drugs were phenytoin (three patients), Isoniazid (two patients), carbamazepine (one patient), nevirapine (one patient), dapsone (one patient), terbinafine (one patient). The patient with dapsone induced erythroderma was diagnosed as a case of lepromatous leprosy and was put on multidrug therapy (dapsone, rifampicin and clofazimine) one month prior to the development of 
erythroderma.

In malignancy induced erythroderma, two patients had mycosis fungoides (MF), one of which was granulomatous slack skin variant; two patients suffering from Hodgkin's lymphoma (HL), mixed cellularity variant.

Despite detailed investigations and multiple serial skin biopsies, no cause could be identified in 13 patients. $(14.7 \%)$ (eight males, five females).

Some aetiologies were significantly associated with certain clinical signs.

1. Subungual hyperkeratosis (34 patients) and psoriasis ( $P$ $=0.0001$ ).

2. Palmoplantar keratoderma (34 patients) and psoriasis ( $\mathrm{P}$ $=0.0001$ )

3. Pruritus ( 30 patients) and psoriasis $(\mathrm{P}=0.001)$

4. Relapses (14 patients) and psoriasis $(\mathrm{P}=0.02)$

5. Longer duration of psoriasis (10 patients) and relapse (P $=0.002$ )

\section{Clinicopathological Correlation}

Skin biopsy was obtained in 62 patients. Three of them had two biopsies (a total of 65 biopsies). Histological examination inferred a specific dermatosis in 42 biopsies (42 / 65:64.6\%). The remaining 23 biopsies (35.3\%) were concluded to non specific dermatitis (Table 2). Most common histopathological findings were perivascular lymphocytic infiltrate $(24 / 65$ biopsies; $36.9 \%$ ) followed by parakeratosis (20 / 65 biopsies; $30.7 \%$ ). The presence of parakeratosis, hypogranulosis, suprapapillary thinning, acanthosis and perivascular lymphocytic infiltrate were suggestive of psoriasis (Figure 1e). Hyperkeratosis, spongiosis, perivascular lymphocytic infiltrate and eosinophils were in favour of eczemas. The presence of parakeratosis, basal cell vacuolization, perivascular lymphocytic infiltrates and eosinophils was suggestive of drug-induced erythroderma.

\section{Lymph Node Biopsy}

In the study, nine lymph node biopsies were performed. Out of which, four biopsies revealed malignancy while five showed dermatopathic lymphadenopathy. Immunohistochemistry was done in four patients with malignancy induced erythroderma which revealed CD 30 positivity in HL and CD 3,4,7 positivity in MF. Lymphadenopathy regressed over a period of 1 - 2 weeks, as an erythrodermic state was treated in dermatopathic lymphadenopathy.

\section{Treatment}

Treatment included a combination of topical and systemic agents. Emollients, moisturizers, topical corticosteroids were a mainstay of topical therapy. Systemic agents administered were methotrexate (32 psoriasis patients), acitretin (8 psoriasis patients), cyclosporine (three psoriasis patients) dexamethasone (six drug reactions, five $A B C D$, four stasis eczema, five ACD, five idiopathic, one mycosis fungoides), chemotherapy (ABVD regimen for one HL patient), PUVA therapy (two psoriasis patients, two idiopathic patients, two MF patients). (Table 1)

\section{Relapses}

Relapse rate was $22.7 \%$ (20 patients) after a mean remission of 5.2 months (median = 3 months) (range: 20 days -2 years) with:

One relapse: 13 patients (psoriasis: 8 patients, MF: 2 patients, idiopathic: 2 patients, ABCD: 1 patient)

Two relapses: 6 patients (psoriasis: 5 patients, ABCD: 1 patient)

Three or more relapses: 1 patient (pustular psoriasis: 1 patient)

Relapse both in terms of the number of patients (14 patients) and the number of episodes (3 episodes) was highest in psoriasis. The case with three relapses was a female patient with generalized pustular psoriasis.

The most common causes of relapse were uncontrolled comorbid disorders (diabetes and hypertension) seen in 12 patients (13.6\%) followed by medication non-adherence seen in five patients $(5.7 \%)$. Other causes being the winter season, parthenium weed and emotional stress

\section{Mortality}

Mortality in our study was observed in six patients (6.8 \%): two patients of MF, one patient of nevirapine induced erythroderma in HIV / AIDS with a CD4 count of 22, three patients of idiopathic erythroderma, sudden cardiac death, acute respiratory distress syndrome were the causes of death.

\section{DISCUSSION}

Erythroderma is uncommon with an incidence of 1 - 2 / 100,000 population. ${ }^{2}$ A prospective study done by Sehgal and Srivastava in India resoluted the incidence to be 35 per 100,000 dermatologic patients, ${ }^{3}$ while another study by Hasan and Jansen also approximated the annual incidence to be 1 to 2 per 100,000 population. ${ }^{4}$ There is a male preponderance in most studies with a male-to-female ratio ranging from $2: 1$ to $4: 1$ and the mean age between 40 and 60 years. ${ }^{2}$ This is similar to our study where the male-to-female ratio was $2.38: 1$ with a mean age of 47.3 years. The onset of erythroderma is usually gradual and insidious. ${ }^{5,6}$ As there is no available standard demarcation of chronic and acute onset erythroderma, we considered the cases with clinical features started in the preceding 2 weeks as acute onset erythroderma. In our study, psoriasis was the only entity that had both acute and chronic onset ranging from 4 days to 2 years. This is in contrast to previous studies where drug-induced erythroderma had acute onset.7,8

Similar to other studies, majority of the clinical features did not correlate with aetiology. Despite varied causes, erythroderma has several common clinical features.2,6,9 In our study, pruritus was found in 49 patients (55.6\%); it was significantly associated with psoriasis $(\mathrm{P}=0.001)$. In previous studies, pruritus was found in a higher percentage of patients. ${ }^{9,10}$ Due to their slower development, nail changes were of potential value in differentiating the underlying cause. ${ }^{11,12,13}$ Nail changes were observed in $72.7 \%$ of cases. The most common nail change was subungual hyperkeratosis (61.3 \%) followed by pitting (22.7\%). Palmoplantar keratoderma was seen in $62.5 \%$ of patients. Both subungual 
hyperkeratosis and palmoplantar keratoderma were commonest in psoriatic erythroderma and the association was statistically significant.

As reported by Eugster et al. ${ }^{14}$ five patients among seven with malignancy-related erythroderma had a history of preexisting psoriasis. Khaled et al. ${ }^{15}$ observed nevirapine induced erythroderma in a well-known psoriatic patient. In the present study, nevirapine precipitated erythroderma in a patient with a past history of psoriasis and isoniazid in a patient with a history of $A B C D$. So, it is imperative to contemplate alternative aetiologies even in patients who may have a comprehensible history of pre-existing dermatoses.7,8,14

Table 3 compares the etiological groups among the recent previous studies and the present study. Etiological factors depend largely on the population studied. Infections as aetiology are seen in countries like India due to environmental factors and poor living conditions.

Pre-existent dermatoses are generally of long duration $^{4,16,17}$ and intractable to therapy. Boyd et al. 16 observed an average of 14 years between the onset of psoriasis and erythroderma. In our study, erythroderma had occurred more frequently in patients with a history of psoriasis (22 /40 cases). Furthermore, psoriatic patients had one or more relapses (14 / 40 cases). In patients with relapses, we have recorded a significantly longer duration of psoriasis with a mean of 2.5 years. So, longer the duration of psoriasis, the more is the risk of relapses.

Eczema is seen in $21.5 \%$ of cases in our study. It may be due to greater exposure of sensitizers in our community when compared to developed countries. History of contact, preexisting venous disease, distribution of original skin lesions pointed towards the aetiology of eczema.

Drugs as an etiologic group were seen in $10.2 \%$ of cases. This is low in comparison to other studies. ${ }^{15,18,19}$ Despite widespread use or misuse and most of the medications being still available over the counter, drugs seem to be a lesser threat in our community. Drugs implicated in the present study are among the most commonly reported in the literature (phenytoin, isoniazid).

Infections as aetiology of erythroderma were seen in only a few studies.9,2 This was due to the differences in socioeconomic and environmental factors. The primary contributing factors in contracting infections seem to be poverty and poor living conditions.

The incidence of malignancy induced erythroderma in our study was $4.5 \%$. There is a wide diversity in its incidence ranging from $1 \%$ to $13 \%$ in various studies. $9,10,20,21,22,23$ This incongruity seems to be connected to the frailty of investigative procedures and surveillance. The age group of patients of malignancy induced erythroderma in our study was younger range in two cases $(28,35$ years) which is in contrast to other studies. ${ }^{15}$

In our study, despite an exhaustive screening, $14.7 \%$ of patients could not be included in a precise aetiology (between $7.2 \%$ and $46 \%$ in the literature) (Table 3). These are categorized under idiopathic disorders and should be kept under close and continual surveillance. Patients with idiopathic erythroderma are many times elderly men (mean age of 64 years, sex - ratio of 6.6:1). ${ }^{24}$ According to Wilson et al. ${ }^{14}$ some patients remit spontaneously, others are eventually identified as some other dermatosis. But, a noteworthy percentage of these patients will develop cutaneous $\mathrm{T}$ - cell lymphoma (CTCL). Hence, idiopathic erythroderma is often regarded as a pre-malignant entity.

In the present study, a clinicopathological correlation was found in $64.6 \%$ of patients. It was of maximum benefit in cases suspected to be related to pre-existing dermatoses and malignancy. The correlation varied between 59 and $74 \%$ in various studies. ${ }^{15,22,25}$ Microscopic clues to diagnosis, if reviewed conventionally, can reveal primary aetiology. Walsh et al. ${ }^{26}$ recommended that multiple serial biopsies from affected skin amplified the validity of the histopathologic diagnosis.

Relapses in our study were found in 20 patients $(22.7 \%)$. Hulmani et al. ${ }^{10}$ Khaled et al. ${ }^{15}$ found relapses in $10 \%$ and 35.7 $\%$ in their studies. The highest number of relapses were found in psoriasis (15.9\%). This has been attributed to coexistent comorbidities, medication non-adherence and use of homoeopathic, Unani, ayurvedic, herbal and common home remedies.

The mortality rate in our study was $6.5 \%$. None of the 6 deaths could be attributed to erythroderma. Overall, the best prognosis was seen in the drug reaction and infection group in other studies, the recorded death rate varied from 18 to 64 $\% .6,17,19,27,28$ Low mortality rate in the present study can be elucidated by a limited surveillance period.

\section{CONCLUSIONS}

Our study would ergo assist the view that erythroderma, although very troublesome to patients, in a majority of cases, is associated with a commending prognosis. Relapses constitute a great menace. Patients should be screened for barriers to medication non-adherence and counselled regarding the importance of taking drugs. Our study suggests a need for more effective comorbidity management and creating awareness regarding judicial use of drugs which can go far in preventing mortality and morbidity in erythroderma.

\section{Limitations}

The study has limitations. The true incidence of erythroderma in our population could not be determined as this was a crosssectional study and no defined population group was available. Also, cases of erythroderma secondary to the cutaneous lymphoma may have been missed due to the lack of further follow-up.

Data sharing statement provided by the authors is available with the full text of this article at jemds.com.

Financial or other competing interests: None.

Disclosure forms provided by the authors are available with the full text of this article at jemds.com.

\section{REFERENCES}

[1] Wong KS, Wong SN, Jham SN, et al. Generalized exfoliative dermatitis: a clinical study of 108 patients. Ann Acad Med Singapore 1988;17(4):520-33.

[2] Sigurdsson V, Steegmans PH, van Vloten WA. The incidence of erythroderma: a survey among all 
dermatologists in the Netherlands. J Am Acad Dermatol 2001;45(5):675-8.

[3] Sehgal VN, Srivastava G. Exfoliative dermatitis: a prospective study of 80 patients. Dermatologica 1986;173(6):278-84.

[4] Hasan T, Jansen CT. Erythroderma - a follow - up of 50 patients. J Am Acad Dermatol 1983;8(6):836-40.

[5] Rym MB, Mourad M, Bechir Z, et al. Erythroderma in adults: a report of 80 cases. Int J Dermatol 2005;44(9):731-5.

[6] Sehgal VN, Srivastava G, Sardana K, et al. Erythroderma / exfoliative dermatitis: a synopsis. Int J Dermatol 2004;43(1):39-47.

[7] Botella-Estradas R, Sanmartin O, Oeiver V, et al. Erythroderma - a clinical pathological study of 56 cases. Arch Dermatol 1994;130(12):1503-7.

[8] Zip C, Murray S, Walsh NM. The specificity of histopathology in erythroderma. J Cutan Pathol 1993;20(5):393-8.

[9] Pal S, Haroon TS. Erythroderma: a clinic - etiologic study of 90 cases. Int J Dermatol 1998;37(2):104-7.

[10] Hulmani M, Nandakishore B, Bhat MR, et al. Clinicoetiological study of 30 erythroderma cases from tertiary center in South India. Indian Dermatology Online Journal 2014;5(1):25-9.

[11] Weinstein, Lie NA, Frost P. Exfoliative dermatitis. In: Joseph DD, edr. In Clinical Dermatology. $6^{\text {th }}$ edn. Philadelphia: Lippincott Company, 1989: p. 1-8.

[12] Vasconcellos C, Domingues PP, Aoki V, et al. Erythroderma: analysis of 247 cases. Rev Saude Publica 1995;29(3):177-82.

[13] Wilson DC, Jester JD, King LE Jr. Erythroderma and exfoliative dermatitis. Clinics in Dermatology 1993;11(1):67-72.

[14] Eugster R, Kisling S, Brand CU. Clinical aspects and aaetiology of erythroderma: an analysis of 64 cases. Praxis (Bern 1994) 2001;90(35):1449-54.

[15] Khaled A, Sellami A, Fazaa B, et al. Acquired erythroderma in adults: a clinical and prognostic study. Journal of the
European Academy of Dermatology and Venereology 2010;24(7):781-8.

[16] Boyd AJ, Menter A. Erythrodermic psoriasis. Precipitating factors, course and prognosis in 50 patients. J Am Acad Dermatol 1989;21(5 Pt 1):985-91.

[17] Rothe MJ, Bernstein ML, Grant-Kels JM. Life threatening erythroderma: diagnosing and treating the "red man". Clin Dermatol 2005;23(2):206-17.

[18] King LE Jr, Dufresne RG Jr, Lowelt GL, et al. Erythrodermareview of 82 cases. South Med J 1986;79(10):1210-5.

[19] Nicolis GD, Helwig EB. Exfoliative dermatitis. A clinicopathologic study of 135 cases. Arch Dermatol 1973;108(6):788-97.

[20] Akhyani M, Ghodsi ZS, Toosi S, et al. Erythroderma: a clinical study of 97 cases. BMC Dermatol 2005;5:5.

[21] Mathew R, Sreedevan V. Erythroderma: a clinicopathological study of 370 cases from a tertiary care center in Kerala. Indian Journal of Dermatology, Venereology and Leprology 2017;83(5):625.

[22] Rym BM, Mourad M, Bechir Z, et al. Erythroderma in adults: a report of 80 cases. Int J Dermtol 2005;44(9):7315.

[23] Karakayli G, Beckham G, Orengo T, et al. Exfoliative dermatitis. Am Fam Physician 1999;59(3):625-30.

[24] Thestrup-Pedersen K, Halkier-Sørensen L, Søgaard H, et al. The red man syndrome/ exfoliative dermatitis of unknown aetiology: a description and a follow-up of 38 patients. J Am Acad Dermatol 1988;18(6):1307-12.

[25] Banerjee S, Ghosh S, Mandal RK. A study of correlation between clinical and histopathological findings of erythroderma in North Bengal population. Indian journal of Dermatology 2015;60(6):549-55.

[26] Walsh NM, Prokopetz R, Tron VA, et al. Histopathology in erythroderma - review of a series of cases by multiple observers. J Cutan Pathol 1994;21(5):419-23.

[27] Sehgal VN, Rege VL. A retrospective study of exfoliative dermatitis. Indian J Dermatol Venereol 1974;40(2):36-9.

[28] Abraham I, McGrathy JJ, Sanders SL. 101 cases of exfoliative dermatitis. Arch Dermatol 1963;87(1):96-101. 